\title{
Socialization in Multicultural Space: Determinations and Conditions
}

\author{
Martsinkovskaya T*, Chumicheva I, Khuzeeva G \\ Institute of Psychology, Russian State University for the Humanities, Moscow, Russia
}

Copyright $(2018$ by authors, all rights reserved. Authors agree that this article remains permanently open access under the terms of the Creative Commons Attribution License 4.0 International License

\begin{abstract}
Relevance and significance of socialization in the modern changing and multicultural space is connected both with social transitivity and expansion of interpersonal and intergroup communication. Globalization and mass migrations of people spread out socialization borders and demand the positive attitude towards norms and standards of native and foreign culture. These assumptions were tested in the course of empirical research of teenager's socialization in the megalopolis (Moscow) and the capital of Karelia Petrozavodsk. Teenagers from Petrozavodsk represent ethnically homogeneous group, the teenagers living in Moscow belonged to 9 ethnic groups. The obtained data showed the general for modern generation of the Russian youth tendency of essential increase of personal identity. In Karelia this tendency connected with orientation to the outside world and "mixed" ethic identity. This phenomenology increase tolerance to uncertainty and raise socialization's potentials in the multicultural environment. The materials received in Moscow allow allocating three levels of determination in teenager's socialization. This is the space of the big city which gives many variants of socialization and can be considered as the translator of common cultural and civil values. The second determinant is development's aims which unite teenagers of different ethnic groups. The third level is the nearest environment of the teenager. The received materials show that for socialization in multicultural environment is extremely important to give teenagers various sociocultural and ethnic patterns of socialization, which give the chance of self-realization in many spheres to teenagers of different ethnic groups.
\end{abstract}

Keywords Socialization, Personal and Social Identity, Multicultural Space

\section{Introduction}

The modern space of socialization requires taking into account new realities from both society and science. At present, the idea of the variability (transitivity) of social space is a fairly common place. However, understanding how these changes affect the personality, content and structure of identity, the process of socialization is still unclear.

The psychological content of the concept "transitivity" incorporates both social transformations, and the variability of social representations and values, and the uncertainty of norms and attitudes [9, 10]. Uncertainty is mainly determined by variability, since it is connected with the fact of multifaceted nature of changes [9]. It should be remembered that transitivity is not only social, external, but also psychological. Therefore, a big gap arises between subjective and objective spaces and times, the relation to them, and to the changes that take place.

Relevance and significance of socialization in the modern changing and multicultural space is connected both with social transitivity and expansion of interpersonal and intergroup communication. Globalization and mass migrations of people spread out socialization borders and demand the positive attitude towards norms and standards of native and foreign culture.

The fluidity and variability of values and norms is, in many ways, the cause of the growing anxiety and tension of people who find it increasingly difficult to adapt to the ever-changing "rules of the game" $[5,6]$. Therefore, we can state that the socialization takes place throughout the life course and we can talk about the principle continuity of the process of socialization. The cardinal and contradictory nature of the changes has led to the uncertainty in the social expectations of people and ambivalence in their attitude to value orientations and norms. This resulted in negative changes in the content of the social identity of the older generation, and, as a consequence, the complexity in transmission of norms and values to the younger generation $[1,14]$.

Particularly relevant and significant the problem of socialization is for the young generation, as there the process of identity formation coincides with the process of 
socialization as a whole. The uncertainty and variability of the development's patterns in this case is associated with the situation of social changes $[7,9]$.

At the same time, the expansion of migration processes and the associated large-scale transformations of the social and cultural context raise the problem of socialization not only for children, but also for adults. Therefore, the concept of resocialization is currently being modernized. The main characteristic of resocialization is the ability for adequate behavior in unforeseen social situations. For children this situation is not directly operative, however, the increasingly manifested resocialization of adults indirectly, but very powerfully, affects their emotional state, as well as the necessity to expand the set of learned norms, standards, languages $[2,15]$. Language socialization is the focus of many investigations $[2,3,15]$, but the transmission of norms and standards in in different social groups is analyzed very rarely, though in big and small cities the process of such transmission is quite different $[10,13]$.

Another important characteristic of modern socialization is the fact that it occur in the conditions of "fluid modernity" $[4,12]$. This fact must be taken into account in constricting the researches and analyzing their results [11]. In stable situations there are certain rigid norms, rules and institutions of socialization, clearly defining the technologies and the results of the influence of adults on adolescents. Modern multidimensional culture presupposes a "liquid" socialization, in which a multifaceted and non-directed impact is possible, and the result can be delayed, latent. One of the variants of such a delayed result is the change in standards of behavior and the increasing prevalence of standards of masculinity not only for boys, but also for girls already at preschool age important characteristic of modern socialization is the fact that it occur in the conditions of "fluid modernity" [2, 3]. In stable situations there are certain rigid norms, rules and institutions of socialization, clearly defining the technologies and the results of the influence of adults on adolescents. Modern multidimensional culture presupposes a "liquid" socialization, in which a multifaceted and non-directed impact is possible, and the result can be delayed, latent. One of the variants of such a delayed result is the change in standards of behavior and the increasing prevalence of standards of masculinity not only for boys, but also for girls already at preschool age [13].

The necessity to understand the factors and determinants of socialization in today's multicultural reality, as well as the trends that determine the formation of the identity of modern adolescents and young people, define the aims of this study.

\section{Participants}

These assumptions were checked in the course of empirical research of teenager's socialization in the megalopolis (Moscow) and the capital of Karelia Petrozavodsk. Teenagers from Petrozavodsk represent ethnically homogeneous group, the teenagers living in Moscow belonged to 9 ethnic groups.

Research was conducted on base:

- $\quad$ several schools of Moscow, 325 teenagers aged from 15 till 17,5 years;

- $\quad$ school in the capital of Karelia Petrozavodsk. 65 pupils of $15-17$ years.

The study was conducted in 2014-2016. All the participants gave their consent to participate in the study.

\section{Methods}

Technique "Socialization". Martsinkovskaya, Khuzeeva, [7], which estimate the level of socialization and emotional comfort;

The questionnaire "Reference Group". Martsinkovskaya, Khuzeeva; [7], which show the preferences in different fields of communication;

The questionnaire on the definition of the structure of identity. Martsinkovskaya, Khuzeeva, [7];

Technique for the study of anxiety. Prihozan [7];

Method for determination of resilience. Martsinkovskaya, Khuzeeva, [7].

\section{Results}

Diagnosis of socialization and resilience of adolescents allowed estimating the level of socialization, emotional comfort and vitality.

In the context of this work the leading indicators were the parameters of adaptation - dis-adaptation, emotional comfort / discomfort, resilience (Fig. 1).

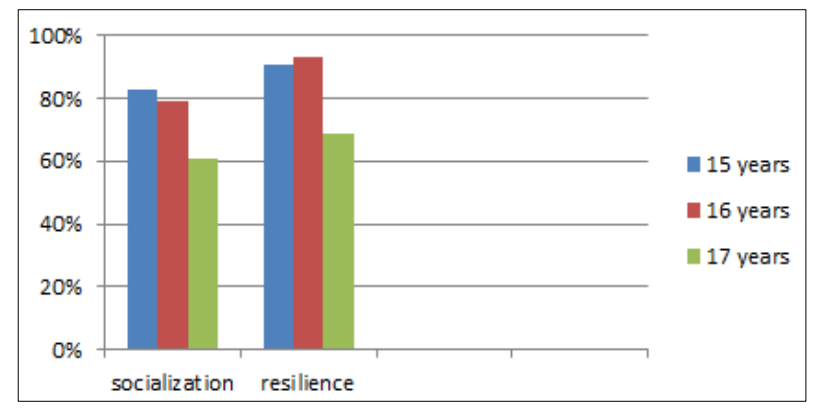

Figure 1. The level of socialization and emotional comfort. Level of resilience.

The obtained data show that, in general, all teenagers from Moscow and Petrozavodsk are well socialized and do not feel emotional discomfort or rejection. They consider the social space in which they live, as a fairly comfortable environment, which allows them to find adequate options for entering and adapting the adult's world. At the same time, it was alarming that all parameters of socialization 
decreased while growing up.

This fact is confirmed by the results obtained in studying the level of anxiety (Fig. 2).

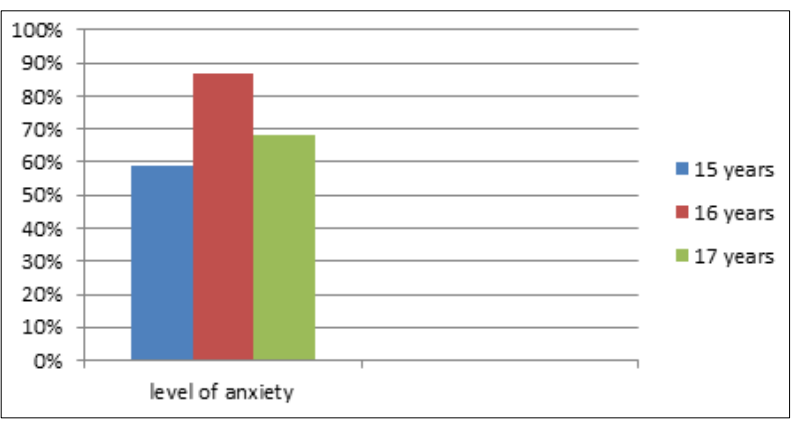

Figure 2. The overall level of personal anxiety and anxiety about the future.
These results show a high level of anxiety for almost all respondents in Moscow and Petrozavodsk. The anxiety of adolescents is manifested, first of all, in relation to the future, which they don't regard as positive and stable. They worry about material aspects of future. It is mainly money for education and capacities to find good work. To a lesser extent, boys and girls are worried about self-realization, the opportunity to find interesting and creative activity.

Teenagers from Petrozavodsk are also concerned about ability to move to Moscow, St. Petersburg or Helsinki and the opportunities for getting education in these big cities.

To analyze the possible reasons for the appearance of differences in socialization strategies in different ethnic groups, we used the "Reference Groups" technique. Analysis of the answers to the question: "with whom you want to spend free time" showed wide spread of answers (Fig. 3).

\begin{tabular}{|c|c|c|c|c|c|c|c|}
\hline Criterion & $\begin{array}{c}\text { Free } \\
\text { time-parents }\end{array}$ & $\begin{array}{c}\text { Free } \\
\text { time-relatives }\end{array}$ & $\begin{array}{c}\text { Free } \\
\text { time-sibling }\end{array}$ & $\begin{array}{c}\text { Free } \\
\text { time-friends, } \\
\text { school }\end{array}$ & $\begin{array}{c}\text { Free } \\
\text { time-people }\end{array}$ & $\begin{array}{c}\text { Free } \\
\text { time-people } \\
\text { culture }\end{array}$ & $\begin{array}{c}\text { Free time-people } \\
\text { interests }\end{array}$ \\
\hline $\begin{array}{c}\text { Kruskal } \\
\text { Wallis Test }\end{array}$ & 62,467 & 92,842 & 49,407 & 17,073 & 39,013 & 34,727 & 11,221 \\
\hline $\begin{array}{c}\text { Asymp. } \\
\text { Sig. }\end{array}$ &, 000 &, 000 &, 000 &, 029 &, 000 &, 000 &, 190 \\
\hline
\end{tabular}

Figure 3. The results of the Kruskal-Wallis comparative analysis on responses to the question "with whom I spend my free time"

At the same time, it should be noted that the main factor determining the group of leisure activities are development tasks, and not ethnic specificity. It can also be assumed that in different everyday situations teenagers of different ethnic samples are oriented either to friends (entertainment, fun, teaching, hobbies) or parents and relatives (everyday situations, home holidays)

This assumption is confirmed by the answers to question "whose opinion is especially important" (Fig 4).

\begin{tabular}{|c|c|c|c|c|c|c|c|}
\hline Criterion & Opinion - parents & $\begin{array}{c}\text { Opinion } \\
\text {-relatives }\end{array}$ & $\begin{array}{c}\text { Opinion } \\
\text {-siblings }\end{array}$ & $\begin{array}{c}\text { Opinion } \\
\text {-friends, school }\end{array}$ & $\begin{array}{c}\text { Opinion } \\
\text {-people }\end{array}$ & $\begin{array}{c}\text { Opinion } \\
\text {-people culture }\end{array}$ & $\begin{array}{c}\text { Opinion } \\
\text {-people } \\
\text { interests }\end{array}$ \\
\hline $\begin{array}{c}\text { Kruskal Wallis } \\
\text { Test }\end{array}$ & 14,395 & 6,891 & 11,189 & 17,046 & 25,385 & 33,962 & 8,571 \\
\hline Asymp. Sig. &, 072 &, 548 &, 191 &, 030 &, 001 &, 000 &, 380 \\
\hline
\end{tabular}

Figure 4. The results of the Kruskal-Wallis comparative analysis on responses to the question "whose opinion is important for me" 
As the obtained results show, for teenagers the most important is the opinion of classmates, as well as people of the same culture. In general, it can be said that for most adolescents, regardless of ethnicity, the opinion of friends is very important, sometime even more important than opinion of relatives. It can be explained by the fact, than in transitive society they share (and developing) general norms, values and standards (clothing, hobbies, leisure time) in communication with friends. At the same time in the family, in everyday situations, teenagers are more focused on the opinion of adults, people, who belong to the same culture.

Despite the importance of relatives, the leading for adolescents is not narrow but wide circle of contacts. All of them are socialized in a broad social space, regardless of ethnicity or place of residence. All of them, first of all, assess themselves from the point of belonging to mankind and, most importantly, to a certain age or professional group (or a group of people with the same hobbies (Fig. 5).

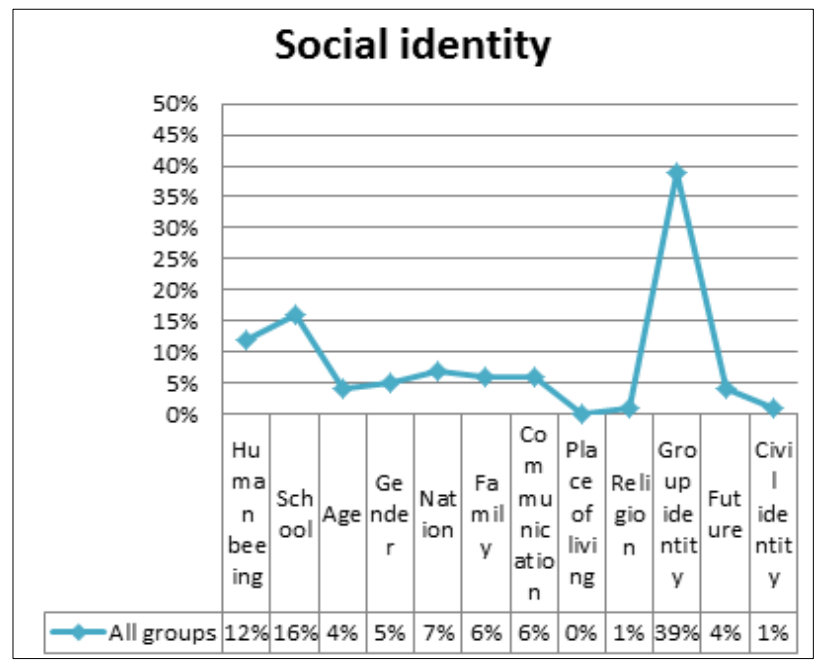

Figure 5. Results "Content of social identity" (average indicators of all groups)

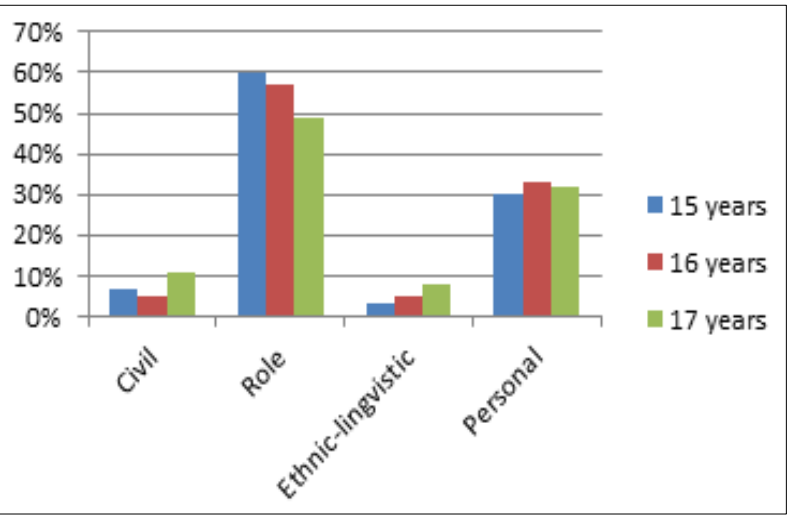

Figure 6. Content of identity in different age groups
As we see, schoolmates and group identity are the main features $\mathrm{n}$ the content of social identity. Nation (ethnic), religion or civil aspects are presented in a very slight extent.

These data are confirmed by the results reveal the content of the identity of all three age groups of respondents (Fig. 6).

The increase of subjective categories in self-descriptions reflects the general age regularity. The fact that in older teenagers and young men this number is approximately the same and slightly larger than that of middle-aged teenagers confirms the tendency to individual and personal self-esteem. At the same time, the share of civil and linguistic identity decreases. The role identity is a very significant, all age groups of respondents, especially older adolescents, consider (and evaluate) themselves precisely from the point of view of conformity / inconsistency to prospective social roles in large, and not small (for example, the family) groups.

\section{Discussion}

Proceeding from the received data, it is necessary to emphasize that the social space both in metropolis and small city, does not destroy teenager's individual patterns of socialization, as they are well adapted and emotionally safe. As for the growing anxiety and the decline in socialization among the older respondents, the results of many researchers $[1,4,5,11]$ show that modern youths living in an ever-changing social world, perceive the situation of transitivity as the norm. Therefore, data that show that fifteen-year-olds are more socialized and emotionally prosperous, in comparison with the seventeen-year-olds, are logical.

The increase in anxiety towards the future to 17-teens also may be connected with the situation of graduation. For teenagers from Petrozavodsk, anxiety is also increasing in connection with their plans to move to big cities. For all youngsters, the question of material well-being is an important frustrating factor that increases their anxiety.

We can state that the high anxiety and uncertainty connected with future increase the identification with the family, which is perceived even by 17 year old boys and girls as a factor that gives stability and certainty in changing conditions and ensures material well-being. At the same time, in solving problems arising in school life and problems related to leisure time, communication circles and etc. the group socialization and identification with friends becomes the leading. (Fig.7).

There are shown correlation links between the indicators of main methods (identity, socialization, resilience). Significant correlation links are marked in bold type (for our group the value of the correlation coefficient is more than $r=0.20$ ). 


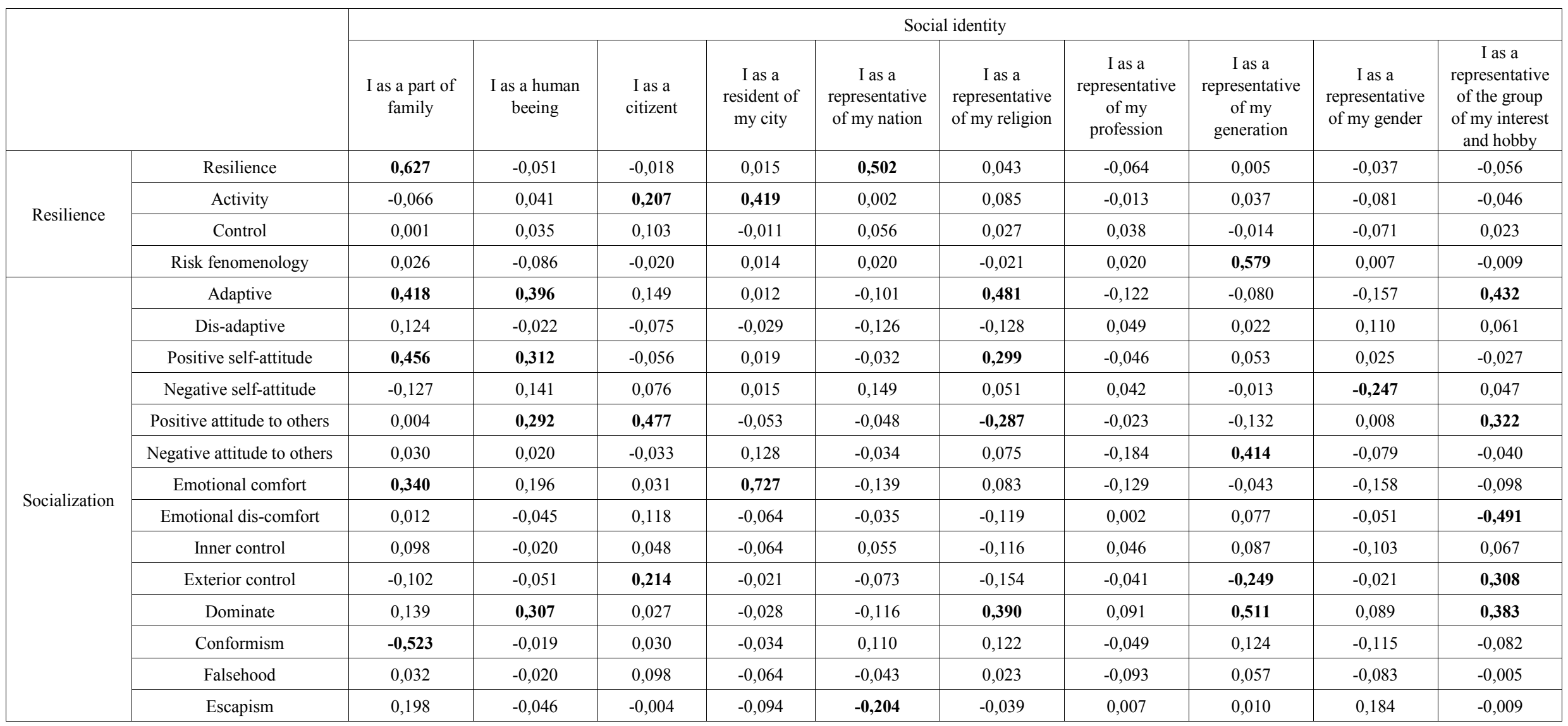

Figure 7. Correlation between identity, socialization, resilience 
These results are also confirmed by our data obtained in the study of schoolchildren residing in not very big towns Kazan and Syktyvkar. [9.12].

Fundamentally new are the data, showing the tendency to increase the share of personal identity and the relationship between identity and socialization. The facts, reviling connection between the number of self-descriptions and the dominance of the personal aspect in identity, as well as the relationship between emotional well-being, anxiety and identity content, are also new.

It was found the relationship between the identity differentiation and the tendency to individualization 0.766 (in analysis was used Mann Whitney U-criterion.). At the same time, the analysis of differences in the identity of adolescents from a megacity and a small city showed that there are significant differences (at $p<0.05$ ) for the following indicators:

- The identity of adolescents from the megalopolis is more ambivalent, in self-description of teenagers from towns are dominating positive self-definitions.

- $\quad$ Adolescents from small towns have a more definite social aspect of identity, in the megalopolis - a personal aspect.

An analysis of the relationship between identity and anxiety has shown that there is a significant positive correlation between the differentiation of identity, that is, the amount of self-description given by the teenagers, and the lowering of anxiety toward the future $(0,341)$. A significant positive correlation was also found between the positive attitude to the future and the dominance of personal identity in the overall structure of identity (0.522).

Thus, it can be assumed that the tendency to individualize the ways of socialization, especially in the megalopolis, is now becoming one of the leading factors that optimize socialization of young people in today's complex multicultural world.

\section{Conclusions}

The obtained materials allow to allocate three levels of determination in teenager's socialization in contemporary large and multi-cultural space. This is the space of a large city that provides extremely wide corridors of positive socialization, allowing most children to find their own identity group and socialize in it. Megacity not only provides many variants of socialization and identity groups, but can be considered as a translator of general cultural and civic values, standards and norms.

The second determinant is development's aims which unite teenagers of different ethnic groups and connected at this stage of ontogeny with the desire to realize themselves, their individuality and their values. This desire also determines the search for different groups of identity, development of different styles of socialization and, ultimately, the development of positive socialization, both in the chosen group and in society as a whole.

The third level is the nearest environment of the teenager. The family role in this case can be considered as the translator of ethnic values and standards of behavior.

Harmonious interaction of all levels of determination provides flexible and variable patterns of socialization. Such interaction is determined not so much by individuality as by the specifics of the social space of a megacity. The presence of a set of subspaces and identity groups (reference groups), makes it possible to self-actualize (or at least present oneself) in different spheres within the framework of different groups. Therefore, all the adolescents who participated in the study are well-socialized and feel themselves comfortably.

The obtained data showed the general for modern Russian youth tendency of essential increase of personal identity. In Karelia this tendency connected with transformation of ethnic identity to "mixed" sociocultural identity. This fact increase tolerance to uncertainty and raising socialization's potentials in the multicultural environment.

The received materials show that for socialization in multicultural environment is extremely important to give teenagers various sociocultural and ethnic patterns of socialization, which give the chance of self-realization in many spheres to teenagers of different ethnic groups.

\section{REFERENCES}

[1] G.M. Andreeva. Presentation of identity in the context of the interaction. Psychological studies. Vol. 5, No 26. 1. 2012.

[2] L. A. Arasaratnam. The development of a new instrument of intercultural communication competence. Journal of Intercultural Communication. No 20. 1-11.2009

[3] N. Arthur. Using critical incidents to investigate cross-cultural transitions. International Journal of Intercultural Relations, 25, 41-53. 2001

[4] Z. Bauman. Liquid modernity. Piter, Saint-Peterburg, 2008

[5] E.P. Belinskaya People in a changing world: socio-psychological perspective. Prometheus, Moscow, 2005 .

[6] E.P. Belinskaya, E.M. Dubovskaya. Variability and constancy as factors of socialization. Psychological studies. Vol. 5, No 7. 5. 2009.

[7] P. Berger, T. Lukman. The social construction of reality. Medium, Moscow, 1995

[8] Identity and socialization in contemporary world. MPGU, Moscow, 2015.

[9] T. Martsinkovskaya The problem of socialization in the historical-genetic paradigm. Smisl, Moscow, 2015.

[10] T. Martsinkovskaya, E. Kiseleva Socialization in 
multicultural space. Psychological studies. Vol. 10, No 53.2. 2017.

[11] R. Harre. Metaphysics and methodology: some recommendations for psycho-social studies. Social psychology: self-reflection of marginality. UNION RAN, Moscow, 1995.

[12] K. Helkama, E. Pohjanhemo. Reflections on values and social instability. Constant in an uncertain and changing world. MGU, Moscow, 2009
[13] G. Khuzeeva. Social identity of adolescents and youths in terms of transitivity. Psychological studies. Vol. 9, No 46. 9. 2016

[14] Parent-child socialization in diverse Cultures. Annual advances in applied developmentalpsychology. V. 5. 1992. Alex publishing corporation. Norwood. New Jersey.

[15] A. Szerlag Socialization models in families as the result of multicultural communication. Santalka: Filosofija, Komunikacija. V. 20, № 2. 136 -146. 2012. 